\title{
Critical Factors Favoring Outward Physician Migration from an Affluent Gulf Country
}

\author{
Satish Chandrasekhar Nair (D) \\ Karthyayani Priya Satish ${ }^{2}$ \\ Halah Ibrahim $^{3}$ \\ 'Department of Academic Affairs, Tawam \\ Hospital, and College of Medicine, United \\ Arab Emirates University, Al Ain, United \\ Arab Emirates; ${ }^{2}$ Medicine Program, \\ Kasturba Medical College, Mangalore, \\ 57500 I, India; ${ }^{3}$ Department of Medicine, \\ Sheikh Khalifa Medical City, Abu Dhabi, \\ United Arab Emirates
}

Background: Physician retention is essential to creating a strong and stable healthcare system worldwide. The density of physicians and nurses significantly impacts important population health outcomes. Globalization has enabled the mobility of physicians, but the recruitment and retention of quality physicians have not been without challenges. The purpose of this study was to identify the outward migration factors affecting expatriate physicians who have resided and worked in the United Arab Emirates (UAE) for at least 5 years, as compared with newly emigrated physicians. This physician population has likely adapted to the local environment and actively contributed to the advancement of medical care in the country; their attrition is a significant loss to the UAE healthcare system.

Methods and Statistical Analysis: A 23-point validated survey questionnaire, consisting of four domains, was electronically administered to the participants $(n=374)$, and responses were statistically analyzed, using descriptive statistics and the Chi-square test.

Results: Our results indicate that all physicians considered a ten-year visa to be factor contributing to retention, more so for the recent physician migrants to the UAE. Professional development opportunities, career-specific plans and income promoted only short-term retention of physicians in the UAE. Non-financial factors related to living and working conditions prevented migration of physicians who lived in the country for more than five years.

Conclusion: Lifestyle-related factors are an important consideration in long-term retention of physicians in the UAE. Initiatives to promote career advancement and improve job satisfaction for mid- and late-career clinicians are necessary to set the foundation for a robust physician retention policy and to enhance the quality of the healthcare system. Long-term visas provide an additional factor for retention.

Keywords: healthcare workforce, manpower planning, physician migration, globalization, retention policies, health systems reform, Middle East

\section{Plain Language Summary}

The migration of physicians from low and middle income to high-income countries has become a global health concern. Health worker migration decisions are influenced by many personal, professional, financial, and political reasons. Our results show that salaries and career-related opportunities contribute to the short-term retention of physicians in the UAE; but lifestyle related factors play a more important role in long-term retention.

\section{Background}

The shortage of skilled health practitioners is a global concern. Studies show that the density of physicians and nurses correlates significantly with important population health outcomes, including life expectancy and infant and child mortality
Correspondence: Satish Chandrasekhar Nair

Email satchi2000@outlook.com 
rates. ${ }^{1}[R E F]$ However, approximately half of countries worldwide do not currently train adequate numbers of healthcare professionals to meet population needs, and rely on the importation of an expatriate health workforce. $^{2}$ Globalization has enabled the increased mobility of health practitioners, primarily from low and middle-income countries to high-income nations, but the recruitment and retention of quality physicians have not been without challenges. The coronavirus 2019 (COVID 19) pandemic has exacerbated the consequences of these physician migration patterns. ${ }^{3}$ The source countries suffer from medical "brain drain" by educating and training practitioners without benefitting from their clinical practice, leading to shortages and weakening of the healthcare systems, leaving them ill-equipped to respond to crises. ${ }^{4} \mathrm{It}$ is estimated that the financial costs associated with excess mortality due to physician migration in low income countries are approximately 15 billion US dollars annually. Studies also suggest that many immigrant clinicians face discrimination, wage disparities, underemployment and deskilling. ${ }^{5}$ For the destination countries, expatriate healthcare practitioners can impose their own cultural values, which may be incongruent with the customs and norms of the society they are serving, resulting in decreased patient satisfaction and low adherence to treatment regimens. ${ }^{6}$ High attrition also leads to the loss of expertise and increased recruitment costs. ${ }^{7}$

The United Arab Emirates (UAE), a high-income Gulf country, offers a unique opportunity to examine health professional migration trends. In recent decades, the UAE has invested substantially in the development of healthcare and education infrastructure. Yet, despite improvements in the quality of medical education and increases in the quantity of medical trainees, ${ }^{8}$ the country has not achieved medical workforce self-sufficiency, primarily due to an aging population and high prevalence of cancer and chronic diseases. ${ }^{9-11}$ Moreover, health systems in the UAE have high turnover rates and retention issues. ${ }^{12}$ A 2012 study, for example, revealed that $12 \%$ of nurses and $15 \%$ of physicians left the UAE workforce in a single year. ${ }^{13}$ Although published national statistics are lacking, in Abu Dhabi, expatriates comprise $87 \%$ of the physician workforce. ${ }^{9}$ The majority of expatriate healthcare workers in the UAE are recruited from neighboring Arab countries, South Asia and Southeast Asia. ${ }^{9}$ Residence visas for physicians are linked to the healthcare facility of employment and require renewal every 3 years. In 2019, 10-year visas were made available to eligible physicians in the country. ${ }^{14}$ This study is part of a larger project evaluating expatriate physician retention in the UAE. We have previously reported that expatriate physicians in the UAE primarily cited lifestyle related factors in their decision to remain in the country, specifically quality of life, proximity to extended family and personal and family safety. ${ }^{15}$ In this study, we look specifically at outward migration intentions of expatriate physicians who have resided and worked in the UAE for at least 5 years, as compared with newly emigrated physicians. This physician population has likely adapted to the local environment and actively contributed to the advancement of medical care in the country; their attrition is a significant loss to the UAE healthcare system.

\section{Methods}

\section{Survey Participants}

Participants included expatriate physicians working and living in the UAE. Inclusion criteria included expatriate (immigrant) physicians, between the ages of 21 and 65 , who were engaged in active medical and dental practice, as verified by their active professional license and national identification card. UAE nationals and participants unwilling to consent were excluded from the study. The expatriate physicians were categorized as: a) actively practicing medicine and living in the UAE for less than 5 years (early immigrants), and b) actively practicing medicine and living in the UAE for 5 or more years (late immigrants).

\section{Survey Administration}

Development and validation of the survey questionnaire has been previously described. ${ }^{15}$ The instrument consists of 23 items, organized into 4 domains, namely work and career, cost and quality of life, family and social life, and health system and regulation. A cross sectional survey was administered between November 2018 and September 2019 to physicians working in public and private hospitals and clinics in 4 emirates in the UAE- Abu Dhabi, Ajman, Ras Al Khaimah and Umm Al Quwain. Physician researchers approached potential respondents during routinely scheduled meetings, conferences and training workshops. Respondents completed selfadministered electronic surveys. Written informed consent to participate in the survey was obtained. No incentives were offered for participation. 


\section{Data Analysis}

Responses were tabulated into two categories: (1) very likely and likely to leave UAE and (2) unlikely and very unlikely to leave UAE, and represented as a percentage of the cumulative response. ${ }^{16}$ Chi-square test was used to analyze the differences between early and late immigrant physicians. Statistical significance was determined and p-value of $\leq 0.05$ was considered statistically significant. The study was reviewed and approved by the Tawam Hospital research ethics committee. The study was conducted in accordance with the Declaration of Helsinki.

\section{Results}

A total of 374 physicians from across the UAE successfully completed the questionnaire. Approximately 52\% (199/374) of the participants lived in the UAE less than 5 years, and were categorized as early immigrants. The remaining 47\% (175/374) of respondents lived in the UAE for 5 or more years, and were categorized as late immigrants. The median duration of UAE employment for the early immigrants and the late immigrants were 3 and 9 years, respectively.

\section{Factors Promoting Outward Migration of Physicians}

Six factors promoted the outward migration of practicing physicians from the UAE, with half from the "Work and Career" category. The factors most frequently reported to encourage physicians to leave their destination country included work hours, job security, job satisfaction, and career advancement, irrespective of duration of employment. Job satisfaction $(125 / 175,71.4 \%, \mathrm{p}<0.05)$, job security $(103 / 175,58.9 \%, \mathrm{p}<0.05)$, extended work hours $(102 / 175,58.3 \%, \mathrm{P}<0.001)$, and lack of career advancement opportunities $(115 / 175,65.7 \%, \mathrm{p}<0.05)$ were more likely to contribute to the migration of the late immigrant physicians, as compared with early immigrant physicians (Table 1). In the "Cost and Quality of Life" domain, cost of living affected both groups of physicians, but only $11.4 \%$ of the late immigrant physicians, compared to $18.1 \%$ of the early immigrant physicians $(p<0.002)$, considered it to be a factor in remaining in the UAE (Table 1). Interestingly, none of the factors from the "Family and Social Life" domain contributed to the outward migration of either group of physicians from the UAE.

\section{Factors Promoting Retention of Late Immigrant Physicians}

Work-life balance was a decisive factor for the late immigrant physicians to remain in the country $(62.9 \%)$, when compared to the early immigrant physicians $(52.3 \%$, $\mathrm{p}<0.01$ ) (Table 2). In fact, work-life balance is the only factor from the "Work \& Career" domain that prevented the exodus. The social environment $(64.6 \%$ vs $47.7 \%$, $\mathrm{p}<0.01)$, spouse's employment opportunity $(58.7 \%$ vs $42.7 \%, \mathrm{p}<0.005)$, and proximity to extended family

Table I Assessment of the Pull Factors Promoting the Outward Migration of Late Immigrant Physicians from the UAE

\begin{tabular}{|c|c|c|c|c|c|c|c|c|c|}
\hline Domain & Factors & $\begin{array}{l}\text { Physician } \\
\text { Category }\end{array}$ & Neutral (n) & Neutral (\%) & Pull (n) & Pull (\%) & $\begin{array}{l}\text { Hold- } \\
\text { Back }\end{array}$ & $\begin{array}{l}\text { Hold- } \\
\text { Back (\%) }\end{array}$ & $P$ value \\
\hline \multirow[t]{2}{*}{ Career \& Work } & Work Hours & Early & 11 & 5.5 & 113 & 56.8 & 75 & 37.7 & $0.00 * * *$ \\
\hline & & Late & 26 & 14.9 & 102 & 58.3 & 47 & 26.9 & \\
\hline \multirow[t]{2}{*}{ Career \& Work } & Job Security & Early & 6 & 3.0 & 113 & 56.8 & 80 & 40.2 & $0.05 * *$ \\
\hline & & Late & 2 & I.I & 103 & 58.9 & 70 & 40.0 & \\
\hline \multirow[t]{2}{*}{ Career \& Work } & Job & Early & 7 & 3.5 & 124 & 62.3 & 68 & 34.2 & $0.05 * *$ \\
\hline & Satisfaction & Late & 13 & 7.4 & 125 & 71.4 & 37 & 21.1 & \\
\hline \multirow[t]{2}{*}{ Career \& Work } & Career & Early & 7 & 3.5 & 135 & 67.8 & 57 & 28.6 & $0.05^{* *}$ \\
\hline & Advancement & Late & 13 & 7.4 & 115 & 65.7 & 47 & 26.9 & \\
\hline \multirow[t]{2}{*}{ Cost \& Quality } & Cost of Living & Early & 11 & 5.5 & 163 & 81.9 & 25 & 18.1 & $0.002 * *$ \\
\hline & & Early & 7 & 3.5 & 148 & 84.5 & 20 & 11.4 & \\
\hline \multirow[t]{2}{*}{ Regulation } & Change Jobs & Early & 18 & 9.0 & 115 & 57.8 & 66 & 33.2 & $0.020 * *$ \\
\hline & & Late & 6 & 3.4 & 105 & 60.0 & 64 & 36.6 & \\
\hline
\end{tabular}

Notes: $\mathrm{n}=$ actual numbers; $\%$ = total percentage; $\mathrm{P}$ value = statistical significance **Significant, ***Highly significant. 
Table 2 Assessment of the Hold-Back Factors Promoting the Retention of Late Immigrant Physicians in the UAE

\begin{tabular}{|c|c|c|c|c|c|c|c|c|c|}
\hline Domain & Factors & $\begin{array}{l}\text { Physician } \\
\text { Category }\end{array}$ & Neutral (n) & Neutral (\%) & Pull (n) & Pull (\%) & $\begin{array}{l}\text { Hold- } \\
\text { Back }\end{array}$ & $\begin{array}{l}\text { Hold- } \\
\text { Back } \\
\text { (\%) }\end{array}$ & $P$ value \\
\hline \multirow[t]{2}{*}{ Career \& Work } & Work-life & Early & 6 & 3.0 & 89 & 44.7 & 104 & 52.3 & $0.01 * *$ \\
\hline & Balance & Late & 6 & 3.4 & 59 & 33.7 & 110 & 62.9 & \\
\hline \multirow[t]{2}{*}{ Family \& Social Life } & Social & Early & 13 & 6.5 & 91 & 45.7 & 95 & 47.7 & $0.01 * *$ \\
\hline & environment & Late & 3 & 1.7 & 59 & 33.7 & 113 & 64.6 & \\
\hline \multirow[t]{2}{*}{ Family \& Social Life } & Spouse & Early & 10 & 5.0 & 104 & 52.3 & 85 & 42.7 & $0.005^{* *}$ \\
\hline & Employment & Late & 23 & 13.1 & 41 & 26.5 & 91 & 58.7 & \\
\hline \multirow[t]{2}{*}{ Family \& Social Life } & Proximity to & Early & 23 & 11.6 & 108 & 54.3 & 68 & 34.2 & $0.01 * *$ \\
\hline & extended family & Late & 17 & 9.7 & 72 & 41.1 & 86 & 49.1 & \\
\hline \multirow[t]{2}{*}{ Cost \& Quality } & Multicultural & Early & 4 & 2.0 & 83 & 41.7 & 112 & 56.3 & $0.000 * * *$ \\
\hline & environment & Late & 0 & 0.0 & 52 & 29.7 & 123 & 70.3 & \\
\hline \multirow[t]{2}{*}{ Cost \& Quality } & Family Safety & Early & 29 & 14.6 & 84 & 42.2 & 86 & 43.2 & $0.03 * *$ \\
\hline & & Late & 11 & 6.3 & 46 & 26.3 & 118 & 67.4 & \\
\hline \multirow[t]{2}{*}{ Cost \& Quality } & Political Stability & Early & 0 & 0.0 & 65 & 41.7 & 134 & 67.3 & $0.040 * *$ \\
\hline & & Late & 4 & 2.3 & 38 & 29.7 & 133 & 76.0 & \\
\hline \multirow[t]{2}{*}{ Cost \& Quality } & Quality of Life & Early & 9 & 4.5 & 91 & 45.7 & 99 & 49.7 & $0.001 * * *$ \\
\hline & & Late & 7 & 4 & 46 & 26.2 & 123 & 70.2 & \\
\hline \multirow[t]{2}{*}{ Regulation } & Health & Early & 46 & 23.1 & 62 & 31.2 & 91 & 45.7 & $0.030 * *$ \\
\hline & Regulation & Late & 14 & 8.0 & 79 & 45.1 & 82 & 46.9 & \\
\hline \multirow[t]{2}{*}{ Regulation } & 10 Year Visa & Early & 12 & 6.0 & 32 & 16.1 & 155 & 77.9 & $0.002^{* *}$ \\
\hline & & Late & 18 & 10.3 & 36 & 20.6 & 121 & 69.1 & \\
\hline
\end{tabular}

Notes: $\mathrm{n}=$ actual numbers; $\%=$ total percentage; $\mathrm{P}$ value $=$ statistical significance ${ }^{* *}$ Significant, ${ }^{* * *}$ Highly significant.

$(49.1 \%$ vs $34.2 \%, p<0.01)$, were also reported to significantly contribute to late immigrant physicians' decisions to remain in the UAE, when compared with their early immigrant counterparts (Table 2). Approximately 70.3\% of the late immigrant physicians considered the multicultural environment to be a positive factor influencing their decision to remain in the UAE (Table 2). Family safety $(67.4 \%)$ and political stability (76\%) also promoted retention of the late immigrant physicians. Quality of life was another significant factor promoting retention of the late immigrant physicians (Table 2). Almost $70.2 \%$ of the late immigrant physicians reported quality of life as a factor to remain in the UAE, as compared with $49.7 \%$ of the early immigrant physicians $(\mathrm{p}<0.001)$. The possibility of obtaining longer-term visas positively influenced both groups of physicians, but more so for the early immigrant physicians (77.9\% vs $69.1 \%, \mathrm{p}<0.002)$ (Table 2).
Competitive income, work load, employment duration, children's education, family's demand to settle elsewhere, value added tax expenses, and peer pressure to succeed were not perceived as significant influencers of retention (Table 3).

\section{Discussion}

Understanding the perceptions of physicians can help policy makers tailor programs to optimize retention strategies. Maintaining a sustainable workforce supports the provision of high-quality healthcare by contributing to increased clinician experience and skill and greater continuity of care for patients. ${ }^{17}$ Consistent with the literature on physician migration, ${ }^{18,19}$ our findings confirm that income and career-specific factors, such as professional development opportunities, can support the short-term retention of health professionals, but do not currently 
Table 3 Assessment of Other Factors That are Neither Enabling (Pull) or Preventing Outward Migration (Hold-Back) of the Immigrant Physicians from the UAE

\begin{tabular}{|c|c|c|c|c|c|c|c|c|c|}
\hline Domain & Factors & $\begin{array}{l}\text { Physician } \\
\text { Category }\end{array}$ & Neutral (n) & Neutral (\%) & Pull (n) & Pull (\%) & $\begin{array}{l}\text { Hold- } \\
\text { Back }\end{array}$ & $\begin{array}{l}\text { Hold- } \\
\text { Back (\%) }\end{array}$ & $P$ value \\
\hline \multirow[t]{2}{*}{ Career \& Work } & Competitive & Early & 9 & 4.5 & 122 & 61.3 & 68 & 34.2 & $0.90^{\dagger}$ \\
\hline & Income & Late & 6 & 3.4 & 109 & 62.3 & 60 & 34.3 & \\
\hline \multirow[t]{2}{*}{ Career \& Work } & Work Load & Early & 23 & 11.6 & 80 & 40.2 & 96 & 48.2 & $0.08^{\dagger}$ \\
\hline & & Late & 9 & 5.1 & 86 & 49.1 & 80 & 45.7 & \\
\hline \multirow[t]{2}{*}{ Career \& Work } & Employment & Early & 9 & 4.5 & 95 & 47.7 & 95 & 47.7 & $0.62^{\dagger}$ \\
\hline & Duration & Late & 3 & 1.7 & 87 & 49.7 & 85 & 48.6 & \\
\hline \multirow[t]{2}{*}{ Family \& Social Life } & Children's & Early & 12 & 6.0 & 147 & 73.9 & 40 & 20.1 & $0.46^{\dagger}$ \\
\hline & Education & Late & 14 & 8.0 & 123 & 70.3 & 38 & 21.7 & \\
\hline \multirow[t]{2}{*}{ Family \& Social Life } & Family & Early & 16 & 8.0 & 108 & 54.3 & 75 & 37.7 & $0.32^{\dagger}$ \\
\hline & Demand & Late & 8 & 4.6 & 92 & 52.6 & 75 & 42.9 & \\
\hline \multirow[t]{2}{*}{ Cost \& Quality } & Expense VAT & Early & 26 & 13.1 & 123 & 61.8 & 50 & 25.1 & $0.490^{\dagger}$ \\
\hline & & Late & 16 & 9.1 & 106 & 60.6 & 53 & 30.3 & \\
\hline \multirow[t]{2}{*}{ Cost \& Quality } & Peer pressure & Early & 20 & 10.1 & 78 & 39.2 & 101 & 50.8 & $0.100^{\dagger}$ \\
\hline & & Late & 33 & 18.9 & 70 & 40.0 & 72 & 41.1 & \\
\hline
\end{tabular}

Notes: $\mathrm{n}=$ actual numbers; $\%=$ total percentage; $\mathrm{P}$ value $=$ statistical significance ${ }^{\dagger}$ Not significant.

influence the long-term retention plans of physicians in the UAE. Non-financial factors regarding living and working conditions had greater impact on duration of stay and long-term retention. Although these physicians may decide to remain in the country because of lifestyle considerations, the unintended consequence of this situation may be the development of a large cadre of mid and late-career physicians that lack job satisfaction or opportunities for career growth and advancement. Studies have shown that improving job satisfaction benefits physician wellbeing and decreases burnout and attrition. ${ }^{20}$ Further, physician career satisfaction directly impacts patient satisfaction and the quality-of-care delivery. ${ }^{21}$ As such, investment in workplace conditions and professional opportunities for physicians in all career stages can positively impact the quality of clinical care provided to UAE patients.

Our findings have several implications for workforce planning and health policy. As several factors influence duration of stay, effective retention strategies must be multi-pronged, and should be directed at both the service and system level. The literature suggests a comprehensive retention strategy, comprised of developing appropriate infrastructure, maintaining sufficient staffing, offering competitive salaries, providing family and social support, and recognizing clinicians that contribute significantly to patient care. ${ }^{21}$ Our results add to the physician migration literature by providing targets for retention strategies for expatriate physicians at all career stages. For early migrant physicians, increasing financial incentives and career opportunities can optimize retention. For physicians already living and working in the destination country for several years, retention strategies should focus on the work environment, fostering support and engagement, and policies that improve work-life balance. It is notable that the vast majority of respondents considered the 10 -year visa to be an important factor in the decision to remain in the country. Several global studies have shown that policies providing job security are positive determinants of physician retention. $^{22}$

Finally, there is limited published data on the effectiveness of retention strategies. Research is necessary to assess the impact of these programs on physician retention and length of stay.

Our findings should be viewed in light of some important limitations. First, participants represent a small cohort of expatriate physicians in the UAE, and may not be generalizable to the larger expatriate physician community. 
Further, responses reflect perceptions and not actual migration intentions. Missing from the analysis is factors influencing the outward migration of physicians who have already left the UAE health system. Also, the survey may not have fully addressed all factors influencing physician migration decisions, such as individual physician characteristics or other employment opportunities. Further, survey questions sought to identify factors contributing to outward migration from the UAE, but did not specify intended migration back to the respondent's home country or to another destination country. Finally, the study focuses on physicians, who comprise an important, but small, subset of the healthcare workforce.

\section{Conclusion}

Physician migration affects the strength and stability of health systems worldwide. Although globalization has enhanced the mobility of physicians, recruitment and retention of quality physicians have not been without challenges. Income, professional development opportunities, and career-specific factors promoted short-term retention of physicians in the UAE. To encourage longterm retention, health policy makers also need to focus on non-financial strategies, including strategies to improve job security and support work-life balance.

\section{Study Participant Consents}

Written informed consents were obtained from all participants per the requirement of the research ethics committee. All applicable ICH-GCP guidelines were adopted during the course of the study. The study was conducted in accordance with the Declaration of Helsinki.

\section{Funding}

No funding was obtained for the study.

\section{Disclosure}

All authors declare no conflicts of interest.

\section{References}

1. El-Jardali F, Jamal D, Abdallah A, Kassak K. Human resources for health planning and management in the Eastern Mediterranean region: facts, gaps and forward thinking for research and policy. Hum Resour Health. 2007;5(1):5-9. doi:10.1186/1478-4491-5-9

2. World Health Organization (WHO). The 2018 update, Global Health Workforce Statistics, World Health Organization. Geneva: WHO; 2018. Available from: https://www.who.int/data/gho/data/themes/ topics/health-workforce. Accessed July 1, 2021.
3. Sreedharan J, Nair SC, Muttappallymyalil J, et al. Case fatality rates of COVID-19 across the globe: are the current draconian measures justified? Z Gesundh Wiss. Epub 2021 Mar 24.

4. Aluttis C, Tewabech B, Frank MW. The workforce for health in a globalized context- global shortages and international migration. Glob Health Action. 2014;7:23611. doi:10.3402/gha.v7.23611

5. Lorenzo FM, Galvez-Tan J, Icamina K, Javier L. Nurse migration from a source country perspective: Philippine country case study. Health Serv Res. 2007;42:1406-1418. doi:10.1111/j.1475-6773.2007.00716.x

6. Daly EB. Health meanings of Saudi women. $J$ Adv Nurs. 1994;21:853-857. doi:10.1046/j.1365-2648.1995.21050853.x

7. Waldman JD, Kelly F, Aurora S, Smith HL. The shocking cost of turnover in health care. Health Care Manage Rev. 2004;29(1):2-7. doi:10.1097/00004010-200401000-00002

8. Ibrahim H, Al Tatari H, Holmboe ES. The transition to competencybased pediatric training in the United Arab Emirates. BMC Med Educ. 2015;15(1):65. doi:10.1186/s12909-015-0340-3

9. Mosaad AT, Younes MZ. Health policies and intervention strategies: a description of current issues and approaches to care of the public health and health care system in the United Arab Emirates. $J$ Health Care Finance. 2014;40(3):86-100.

10. Nair SC, Hassen WA, Sreedharan J, Qawasmeh K, Ibrahim H. Comparison of perceptions of unmet supportive care needs between cancer patients and their oncologists. Support Care Cancer. 2019;27 (11):4229-4235. doi:10.1007/s00520-019-04705-4

11. Nair SC, Ibrahim H, Celentano DD. Clinical trials in the Middle East and North Africa (MENA) region: grandstanding or grandeur? Contemp Clin Trials. 2013;36(2):704-710. doi:10.1016/j.cct.2013.05.009

12. EMRO. World Health Day advisory toolkit; 2006. Available from: http://www.emro.who.int/WHD2006/kit-brochure-part4.htm. Accessed July 1, 2021.

13. US-UAE Business Council. The UAE healthcare sector. Washington, DC; 2021. Available from: http://usuaebusiness.org/wp-content/uploads/2019/ 01/2021-U.A.E.-Healthcare-Report.pdf. Accessed July 1, 2021.

14. First Post UAE. Available from: https://www.firstpost.com/world/ uae-expands-eligibility-for-10-yr-golden-residency-visa-to-includemore-professions-9016601.html. Accessed July 1, 2021.

15. Ibrahim H, Al Sharif FZ, Satish KP, Hassen L, Nair SC. Should I stay or should I go now? The impact of "pull" factors on physician decisions to remain in a destination country. Int $J$ Health Plann Manage. 2019;34(4):e1909-e1920. doi:10.1002/hpm.2819

16. Sullivan GM, Artino AR. Analyzing and interpreting data from likert-type scales. $J$ Grad Med Educ. 2013;5(4):541-542. doi:10.4300/JGME-5-4-18

17. Alameddine M, Saleh S, El-Jardali F, Dimassi H, Mourad Y. The retention of health human resources in primary healthcare centers in Lebanon: a national survey. BMC Health Serv Res. 2012;12(1):419. doi:10.1186/1472-6963-12-419

18. Barnighausen T, Bloom D. Financial incentives for return of service in underserved areas: a systematic review. BMC Health Serv Res. 2009;9(1):86. doi:10.1186/1472-6963-9-86

19. Myhren H, Ekeberg Ø, Stokland O. Job satisfaction and burnout among intensive care unit nurses and physicians. Crit Care Res Pract. 2013;2013:786176.

20. DeVoe J, Fryer GE, Hargraves JL, Phillips RL, Green LA. Does career dissatisfaction affect the ability of family physicians to deliver high-quality patient care? J Fam Pract. 2002;51(3):223-228.

21. Buykx P, Humphreys J, Wakerman J, Pashen D. Systematic review of effective retention incentives for health workers in rural and remote areas: towards evidence-based policy. Aust J Rural Health. 2010;18 (3):102-109. doi:10.1111/j.1440-1584.2010.01139.x

22. El Koussa M, Atun R, Bowser D, Kruk ME. Factors influencing physicians' choice of workplace: systematic review of drivers of attrition and policy interventions to address them. $J$ Glob Health. 2016;6(2):020403. doi:10.7189/jogh.06.020403 


\section{Publish your work in this journal}

Risk Management and Healthcare Policy is an international, peerreviewed, open access journal focusing on all aspects of public health, policy, and preventative measures to promote good health and improve morbidity and mortality in the population. The journal welcomes submitted papers covering original research, basic science, clinical \& epidemiological studies, reviews and evaluations, guidelines, expert opinion and commentary, case reports and extended reports. The manuscript management system is completely online and includes a very quick and fair peer-review system, which is all easy to use. Visit http://www.dovepress.com/testimonials.php to read real quotes from published authors. 